\title{
Atmospheric monitoring with a spectrographic imager
}

\author{
R. P. SINGH†*, C. OLBERT, C. LINDEMANN, M. SCHAALE \\ and R. FURRER: \\ Institute for Space Sciences, Free University Berlin, Fabeckstr. 69, \\ D-14195 Berlin, Germany
}

(Received 20 October 1995; in final form 20 September 1996)

\begin{abstract}
A compact airborne spectrographic imager (CASI) mounted on top of an attitude stabilizing platform inside a Cessna 207T was used to monitor changes in and around a lake near Berlin for 4 months in 1993-1994. The radiance was recorded at three different altitudes in the wavelength range $0 \cdot 4-0 \cdot 9 \mu \mathrm{m}$. The observed radiances were found to be different from 1 month to another due to the variability of phytoplankton and suspended solids in the lake. The observed radiance was similar when measured at three different altitudes during the same month, whereas the effect of altitude was seen when comparing the radiances from month to month. The radiances in the month of May 1994 have been found to be anomalous when comparing the radiances measured at the altitudes 1500 and $2000 \mathrm{~m}$ in the months of July and September 1993 and February 1994. This anomaly was found to be associated with aerosol concentration around an altitude of 1500-2000 $\mathrm{m}$ in the atmosphere as compared with LOWTRAN modelling.
\end{abstract}

\section{Introduction}

The incident solar radiations are selectively absorbed and re-emitted by the planetary surfaces covered with water, vegetation, forest and built up areas. The re-emitted wavelengths undergo characteristic changes that are typical of surface features. A further shift in the re-emitted radiations are produced as a result of scattering processes from aerosol composition while propagating upwards. Measurements of spectral features of these radiations are extensively used as a diagnostic tool for assessment of aerosol content and classification of global conditions. The spectral features of re-radiated surface radiations do not change very fast. The day to day changes in the re-radiated spectrum arises due to varying composition and density of aerosol content. The radiative forcing due to industrial discharges in the atmosphere is important because of the climatic perturbations (Charlson et al. 1992). Further it is becoming apparent that anthropogenic aerosol exerts radiation influence of climatic changes comparable to changes in the greenhouse effect but opposite in sign. The tropospheric aerosol exerts a cooling influence arising from scattering of shortwave radiation. Using a network of several hundred thermopile pyranometers, a highly variable reduction in solar radiation was recorded during 1958, 1965, 1975 and 1985 (Stanhill and Moreshet 1992, 1994). The reduction in recorded solar radiation is found to be correlated with enhanced exhaust of motor

* Author to whom correspondence should be adddressed.

$\dagger$ Present address: Department of Civil Engineering, Indian Institute of Technology, Kanpur-208 016, India.

tDeceased. 
vehicles on the highway adjacent to the measurement site (Stanhill and Moreshet 1992). Browell et al. (1992) carried out measurements of ozone and aerosol distributions using an airborne lidar system in the Arctic and sub-Arctic regions and found plumes in the tropospheric region which greatly enhanced the scattered intensity. The intent of this letter is to report the results of radiance measurements over a lake of $10 \mathrm{Km}^{2}$ at three different altitudes for the months of July and September 1993, and February and May 1994. The measured radiances have been qualitatively compared with the corresponding radiance using the LOWTRAN modelling program (Kneizys et al. 1988). By comparing computed and observed radiances, it has been found that the scattering processes for urban models dominate above an altitude of $1500 \mathrm{~m}$. This striking correlation seems to arise due to concentration of either water vapour or carbon in the form of soot (Bolle et al. 1986, Cess et al. 1989, Sinha and Harries 1995). Using the quantitative and qualitative nature of routine measurement of measured radiance, the composition and concentration of aerosol in the atmosphere could be estimated and monitored.

\section{Results and discussion}

Measured radiance using CASI are shown in figure 1. The chosen flight levels were dependent on weather conditions differed slightly from month to month. The observed difference in measured radiance in the wavelength range $0.4-0.9 \mu \mathrm{m}$ were attributed to the presence of suspended solids and phytoplankton in the lake (Olbert et al. 1994). These changes also were seen in the radiance measured at different altitudes. From figure 1, we find a prominent peak in the months of July 1993 and May 1994, whereas the peak is less pronounced in the month of September 1993. The variability from month to month was attributed to the decrease in temperature of lake water. From figure 1, it is seen that the radiance was always higher during the summer months as compared to the radiance that was observed in September. The exception was the observed radiance in the month of February which was found to be higher. The higher magnitude of radiance was related to higher albedo of water surface which is due to the presence of a thin layer of snow and ice.

Comparing radiances that were measured at three different altitudes, it was clearly seen that the radiance observed in the months of July and September 1993 increased with increasing altitude. In May 1994, however radiances measured at about $1500 \mathrm{~m}$ above ground level (AGL) were found to be higher compared to measured radiances around an altitude of $2000 \mathrm{~m}$. The measured total radiances were found to decrease with increasing altitude. The increase in radiance was due to light scattering from aerosol at higher altitudes. Due to the combined effect of aerosol concentration in the atmosphere and scattering, the measured radiances were seen to increase with increasing altitude as depicted by measurements. Comparing measured radiance at about $2000 \mathrm{~m}$ and $1500 \mathrm{~m}$, an anomalous behaviour of radiance in the month of May 1994 was found. The observed radiance around $2000 \mathrm{~m}$ was found to be lower compared to $1500 \mathrm{~m}$ and the contrast was almost the same in the months of July and September 1993. The significant contrast was seen in the month of February 1994 in the wavelength range $0 \cdot 4-0 \cdot 9 \mu \mathrm{m}$. It is seen from figure 1 that the contrast in the observed radiance at two altitudes around 1500 and $2100 \mathrm{~m}$ are larger in the month of February. This change in contrast seems to arise due to variability in the meteorological parameters, although it is difficult to pin point the real cause giving rise to such a contrast. 

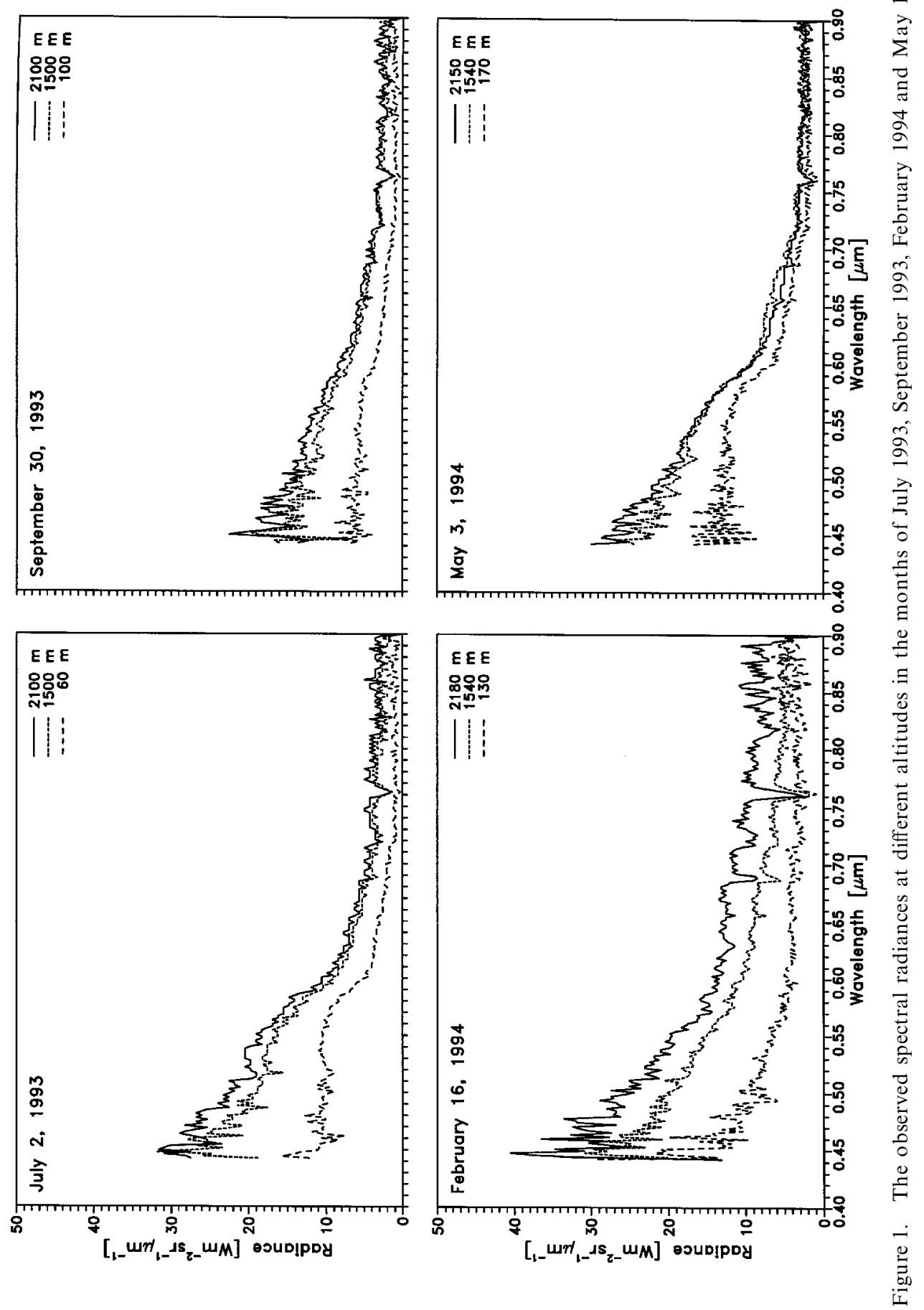

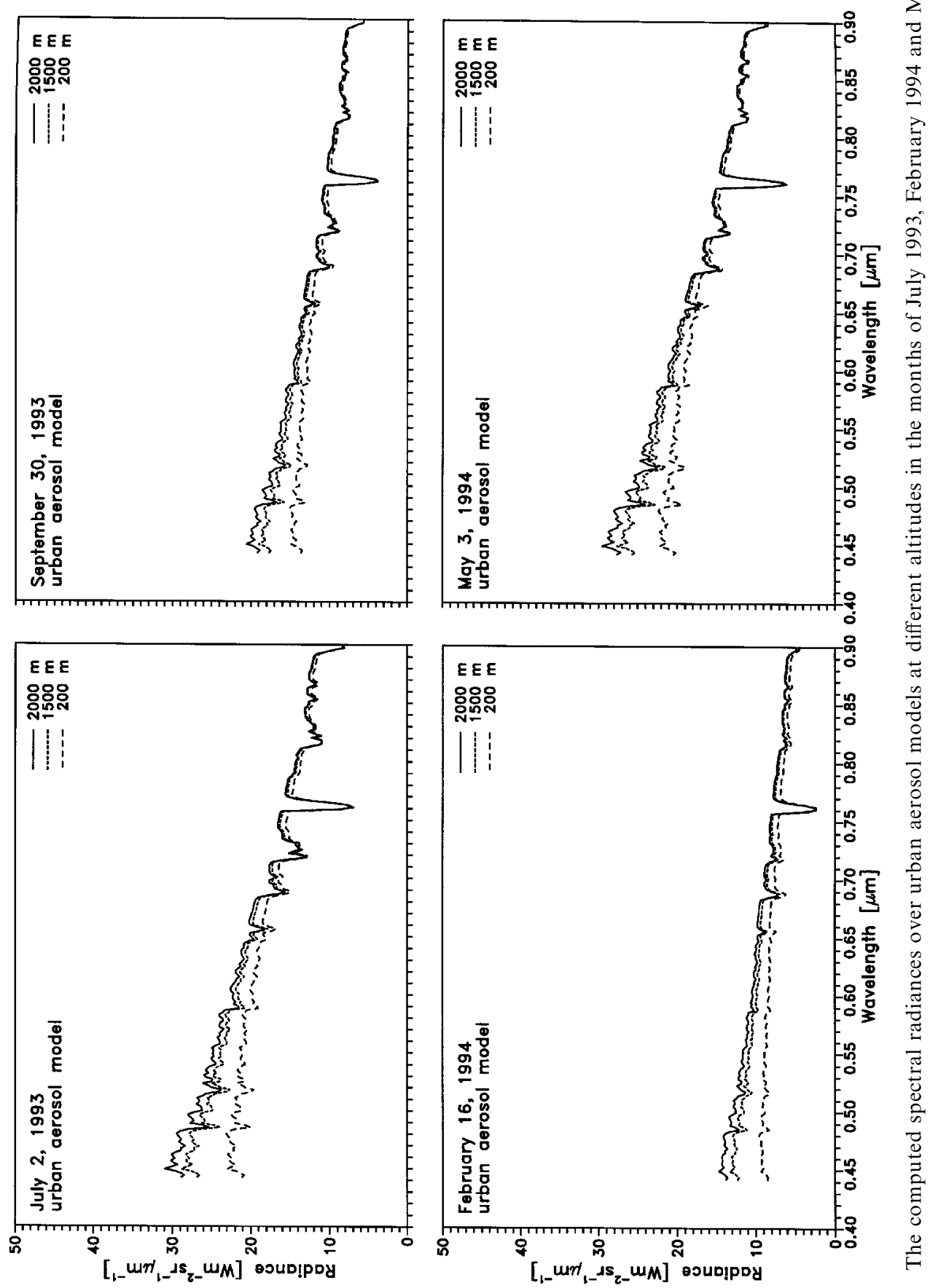


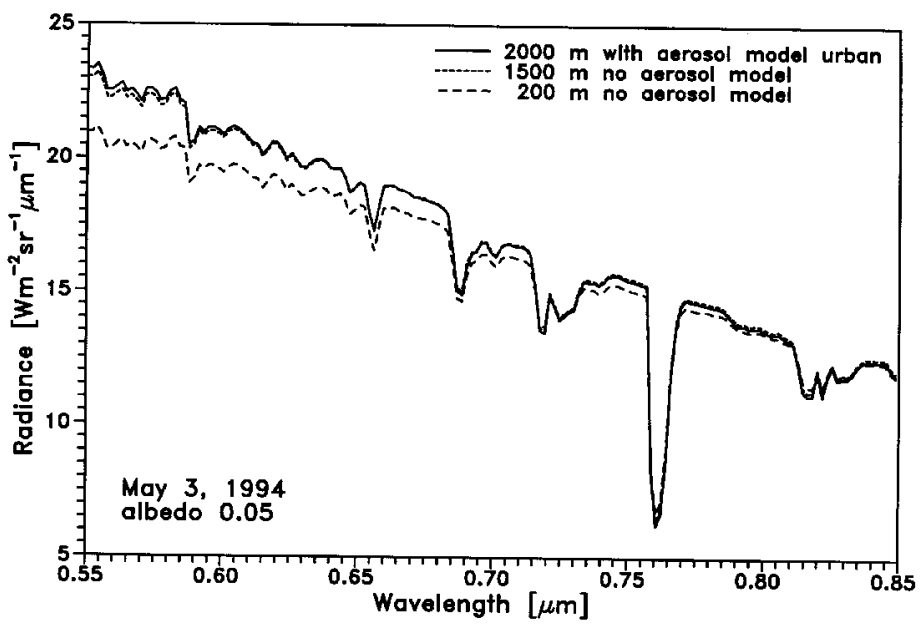

Figure 3. The computed spectral radiances at around 200 and $1500 \mathrm{~m}$ over no aerosol models and computed spectral radiances at about $2000 \mathrm{~m}$ over urban aerosol model.

The observed radiance is compared with theoretically calculated radiance using a LOWTRAN program (Kneizys et al. 1988). The radiance at three altitudes in the months of July and September 1993 and February 1994 were found to show variations similar to that exhibited by an urban aerosol model (figure 2). The nature of radiance in the month of May 1994 as shown in figure 2 is found to be significantly different as compared to measured radiance. Using detailed LOWTRAN modelling and neglecting the attenuation of radiance, the nature of radiance for the month of May 1994 is obtained and shown in figure 3. For obtaining the desired matching of calculated radiance with the measured radiance, the lake albedo was taken to be 0.05 . It is well known that water albedo is wavelength dependent but for the sake of computational simplicity, a constant value was used here. The total radiance recorded by an airborne spectrographic sensor during a 4 month period was found to increase with the increasing altitude. This increase seemed to arise due to the scattering by aerosol. The measured radiances at three altitudes in the month of May, 1994 were found to fit well with the aerosol free model of the lower atmosphere. The nature of variations seen in figure 3 during the month of May, 1994 depict the aerosol concentration in the altitude range above $1500 \mathrm{~m}$ which results in a decrease in radiances recorded at $2000 \mathrm{~m}$. The observed radiance was known to decrease with altitude due to the increase of scattering by the presence of aerosol in the atmosphere. The decrease in radiance at $2000 \mathrm{~m}$ compared to $1500 \mathrm{~m}$ was only possible in terms of enhanced absorption of reflected and scattered radiations by aerosol in the altitude range $1500-2000 \mathrm{~m}$. This was consistent with the result of LOWTRAN modelling.

\section{Conclusions}

The observed anomalous increase of radiance at $1500 \mathrm{~m}$ in the month of May 1994 was found to be higher in the longer wavelength region $(0.57-0.90 \mu \mathrm{m})$ (figure 2). This observation is consistent with earlier findings of other workers namely $(i)$ in the case of urban aerosol containing a high percentage of carbon in the form of soot (Bolle et al. 1986) and (ii) in the presence of water vapour (Cess et al. 1989, Sinha and Harries 1995) in the atmosphere. Therefore, from the observed and modelled 
results reported in this letter, we conclude that the aerosol with a high concentration of carbon particles was present in the atmosphere above $1500 \mathrm{~m}$ around the city of Berlin. This was further supported by the absence of any anomalous water vapour as shown by the measured meteorological parameters in the vicinity of the measurement site. On the other hand, the trapping of aerosol in the tropospheric region was normal and was measured by Browell et al. (1992). They showed that the scattering aerosol was trapped at some places in the atmosphere upto an altitude of $6 \mathrm{~km}$. The radiance modelling results showed that in the month of May 1994 aerosol was concentrated at an altitude above $1500 \mathrm{~m}$ whereas in other months scattering aerosol was spread from the Earth's surface. These results show the qualitative role of aerosol affecting the radiations recorded by the spectrographic imager around 1500-2000 $\mathrm{m}$. For quantitative evaluation, detailed measurements at different altitudes were required. The results reported here show that the airborne spectrographic imager in the spectral mode can be used in the mapping and monitoring of atmosphere. These results are likely to provide additional insight to the remote sensing community engaged in the problems of atmospheric corrections specially in cases of remote sensing data using low altitude platforms.

\section{Acknowledgements}

We are thankful to Peter Koepke, W. Armbruster, Thomas Heinemann, and L. Schuller for discussions. R.P.S. is thankful to Alexander von Humboldt Foundation for the award of research fellowship. We are grateful to Professor Paul Curran and to the anonymous reviewers for their comments.

\section{References}

Bolle, H.-J., Seiler, W. and Bolin, B., 1986, Other greenhouse gases and aerosol: assessing their role for atmospheric radiative transfer. In: The Greenhouse Effect Climatic Change and Ecosystem. edited by B. Warrick and D. Jager (Chichester: John Wiley and Sons), pp. 157-203.

Browell, E. V., Butler, C. F., Kooi, S. A., Fenn, M. A., Harriss, R. C. and Gregory, G. L., 1992, Large scale variability of ozone arctic and sub-arctic troposphere. Journal of Geophysical Research, 97, 18743-18758.

Cess, R. D., Plotter, G. L., Blanchet, J. P., Boer, G. J., Ghan, S. J., Kiehl, J. T., Letreut, H., Li, Z. X., Liang, X. Z., Mitchell, J. F. B., Morcrette, J. J., Randall, D. A., Riches, M. R., Roeckner, E., Schlese, V., Slingo, A., Taylor, K. E., W AShington, W. M., Wetherald, R. T. and YAGAi, I., 1989, Interpretation of cloudclimate feedback as produced by 14 atmospheric general circulation models. Science, 245, 513-516.

Charlson, R. J., Schwartz, S. E., Hales, J. M., Cess, R. D., Coakley, J. A., Hansen, J. E. and Hofmann, D. J., 1992, Climatic forcing by anthropogenic aerosols. Science, 255, 423-430.

Kneizys, F. X., Shettle, E. P., Abreu, L. W., Chetwynd, J. H., Anderson, G. P., Gallery, W. O., Selby, J. E. A. and Clough, S. A., 1988, Users Guide to LOWTRAN 7, AFGL-TR-88-0177, Air Force Geophysical Laboratory, Hanscom AFB, MA 01731, USA.

Olbert, C., Singh, R. P., Schaale, M. and Furrer, R., 1994, Monitoring of water with an airborne spectrographic imager. Proceedings of the First Airborne Remote Sensing Conference and Exhibition, Strasbourg, France, 11-15 September, 1994, volume 3 (Ann Arbor, MI: ERIM), pp. 141-151.

Sinha, A. and Harries, J. E., 1995, Water vapor and greenhouse trapping: the role of far infrared absorption. Geophysical Research Letters, 22, 2147-2150.

Stanhill, G. and Moreshet, S., 1992, Global radiation climate changes: the world radiation network. Climate Change, 21, 57-75.

Stanhill, G. and Moreshet, S., 1994, Global radiation climate change at seven sites remote from surface sources of pollution. Climate Change, 26, 89-103. 